\title{
Phenylethynylbenzenesulfonamide regioisomers strongly and selectively inhibit the transmembrane, tumor-associated carbonic anhydrase isoforms IX and XII over the cytosolic isoforms I and II
}

\author{
Edward E. Knaus ${ }^{\mathrm{a}}$, Alessio Innocenti ${ }^{\mathrm{b}}$, Andrea Scozzafava ${ }^{\mathrm{b}}$, Claudiu T. Supuran ${ }^{\mathrm{b}, *}$ \\ a University of Alberta, Faculty of Pharmacy, Edmonton, Alberta, Canada T6G 2N8 \\ b Università degli Studi di Firenze, Polo Scientifico, Laboratorio di Chimica Bioinorganica, Rm. 188, Via della Lastruccia 3, 50019 Sesto Fiorentino (Florence), Italy
}

\section{A R T I C L E I N F O}

\section{Article history:}

Received 11 June 2011

Revised 23 July 2011

Accepted 25 July 2011

Available online 30 July 2011

\section{Keywords:}

Carbonic anhydrase

Isoforms I, II, IX, XII

Alkynylsulfonamide

Isoform-selective inhibitor

Antitumor lead

\begin{abstract}
A B S T R A C T
A series of compounds incorporating regioisomeric phenylethynylbenzenesulfonamide moieties has been investigated for the inhibition of four human carbonic anhydrase (hCA, EC 4.2.1.1) isoforms, hCA I, II, IX and XII. Inhibition between the low nanomolar to the milliomolar range has been observed against them, with several low nanomolar and tumor-CA selective inhibitors detected. The position of the sulfamoyl group with respect to the alkyne functionality, and the nature of the moieties substituting the second aromatic ring were the principal structural features influencing CA inhibition. The para-sulfamoyl-substituted derivatives were effective inhibitors of CA IX and XII, the meta-substituted regioisomers of CA I IX and XII, whereas the ortho-substituted sulfonamides were weak inhibitors of CA I, II and IX, but inhibited significantly CA XII.
\end{abstract}

(c) 2011 Elsevier Ltd. All rights reserved.
One of our groups reported ${ }^{1}$ a series of compounds incorporating regioisomeric phenylethynylbenzenesulfonamide moieties which has been investigated for the inhibition of cyclooxygenases (COX) 1 and 2. The leads for this type of COX inhibitors are the sulfonamide coxibs, such as celecoxib CLX and valdecoxib VLX, which were widely clinically used nonsteroidal anti-inflammatory drugs (NSAIDs) in the past years, before the withdrawal of rofecoxib RFX from the market. ${ }^{2,3}$ However, unlike the sulfone RFX, primary sulfonamides such as CLX and VLX also inhibit other enzymes, such as the carbonic anhydrases (CAs). ${ }^{4}$ CLX is still clinically used and seems to possess additional clinical effects to the anti-inflammatory ones related to COX inhibition, among which are antitumor properties. ${ }^{3 \mathrm{a}}$

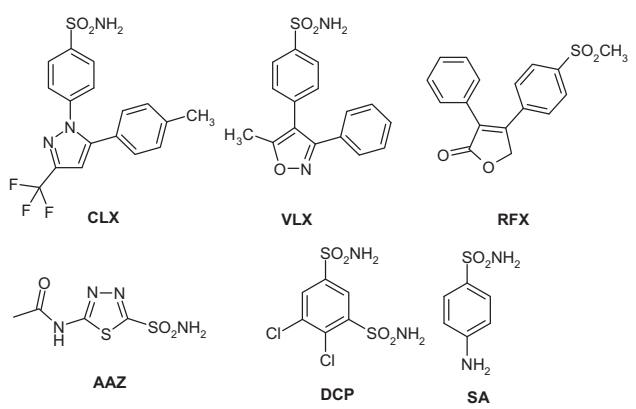

\footnotetext{
* Corresponding author. Tel.: +39 055457 3005; fax: +39 0554573385 .

E-mail address: claudiu.supuran@unifi.it (C.T. Supuran).
}

The CAs (EC 4.2.1.1) are metalloenzymes which catalyze a simple but fundamental reaction, the hydration of carbon dioxide to bicabonate and protons. ${ }^{5}$ Among the 16 different isoforms described so far in mammals, CA IX and CA XII have recently been shown to be druggable targets for imaging and treatment of hypoxic tumors. ${ }^{5-13}$ CA IX is one of the most strongly overexpressed genes in response to hypoxia in a high number of human cancer cells. ${ }^{6,7}$ This enzyme is a multidomain protein ${ }^{5,6}$ with the CA subdomain situated outside the cell and possessing a very high $\mathrm{CO}_{2}$ hydrase catalytic activity. ${ }^{6-8}$ This makes CA IX a key player in the regulation of the tumor $\mathrm{pH}^{6,7} \mathrm{CA}$ IX expression is strongly increased in many types of solid tumors, such as gliomas/ependymomas, mesotheliomas, papillary/follicular carcinomas, as well as carcinomas of the bladder, uterine cervix, kidneys, esophagus, lungs, head and neck, breast, brain, vulva, and squamous/basal cell carcinomas, among others. ${ }^{8,9}$ Furthermore, such hypoxic tumors do not generally respond to the classic chemo- and radiotherapy, and the strong acidification produced by CA IX overexpression also triggers the development of metastases. ${ }^{8,9}$ Another isoform which is sometimes associated with cancers is CA XII, which similar to CA IX is a transmembrane enzyme with an extracellular active site and good activity for the hydration of $\mathrm{CO}_{2}$ to bicarbonate and protons. ${ }^{11,13}$ Recently, it has been shown by several groups ${ }^{6-13}$ that the genetic silencing or pharmacologic inhibition of CA IX and XII have a strong anticancer effect, with growth delay of both the primary tumor and the metastases. ${ }^{10-14}$ 
Sulfonamides represent one of the classical chemotypes associated with potent $C A$ inhibition. ${ }^{5}$ They bind in deprotonated form to the $\mathrm{Zn}(\mathrm{II})$ ion from the enzyme active site interfering with the catalytic process which needs a zinc hydroxide functionality within the enzyme active site. ${ }^{5}$ Indeed, many aromatic, heterocyclic, aliphatic and sugar sulfonamides showed activities in the range of the low micromolar to the low nanomolar for inhibiting various CA isoforms, among which also include CA IX and XII. ${ }^{5-15}$ However, the mammalian CA family comprises 16 isoforms, 13 of which are catalytically active and most of which are indiscriminately inhibited by classical sulfonamide CA inhibitors (CAIs) such as acetazolamide AAZ, dichlorophenamide DCP or sulfanilamide SA ${ }^{5,15}$ These and other sulfonamides are in clinical use as diuretics, antiglaucoma, anticonvulsant or antiinfective drugs for more than 50 years. ${ }^{5,15}$ The strong correlations between CA IX/XII and tumors, and the possibility to inhibit these enzymes by sulfonamides and other CAIs, envisages the use of specific CA IX/XII inhibitors as antitumor drugs and diagnostic agents for hypoxic tumors, a rather new and unexpected application for sulfonamide CAIs. ${ }^{5,14,15}$ Thus, there is a stringent need to design specific CAIs for the tumor associated isoforms CA IX and XII, which should possess decreased affinity for the main offtarget CA isoforms (CA I and II, which are rather abundant in many tissues and participate in important physiological processes).$^{5,12-15}$ Continuing our interest in the investigation of various classes of CAIs, we report here the evaluation as enzyme inhib- itors of the regioisomeric phenylethynylbenzenesulfonamides reported by Knaus's group earlier, ${ }^{1}$ and investigated for their interaction with the COX isoforms. It should be mentioned that although thousands of sulfonamides have been synthesized and investigated for the inhibition of various CA isoforms, alkyne sulfonamides have not yet been included in such studies. ${ }^{16}$

Compounds 1-3 and standard CAIs of the sulfonamide type ( $A A Z$, DCP and SA) were screened for the inhibition of the tumor-associated isoforms hCA IX and XII ( $h=$ human isoform) as well as the offtarget, cytosolic hCA I and II (Table 1). ${ }^{17-22}$

The following structure-activity relationship (SAR) data has been observed for the inhibition of these four CA isozymes with sulfonamides 1-3 :

(i) Against the cytosolic, slow isoform hCA I, the ortho-substituted compounds 3a-3c showed very weak inhibitory action, with $\mathrm{K}_{\mathrm{I}} \mathrm{S}$ in the millimolar range $(0.41-0.80 \mathrm{mM}$, Table 1). Weak inhibition has also been observed for two of the para-substituted derivatives, $\mathbf{1 a}$ and $\mathbf{1 b}$, with $K_{\mathrm{I}} \mathrm{S}$ in the range of $5.59-5.65 \mathrm{M}$. These compounds possess the unsubstituted (1a) or the para-tolyl (1b) moiety attached to the alkyne functionality. However, the remaining parasubstituted sulfonamides 1c-1e as well as the meta-substituted regioisomers $\mathbf{2 a - 2 d}$, showed enhanced inhibition against hCA I, with $K_{\mathrm{I}} \mathrm{S}$ in the range of 59-102 nM (Table 1).

\section{Table 1}

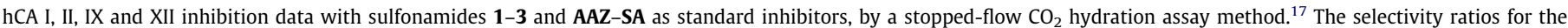
inhibition of the tumor-associated over the cytosolic isoforms are also provided

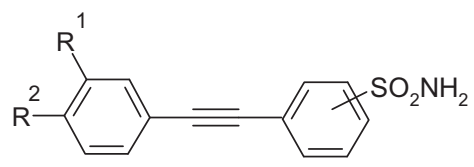

$1-3$

$\begin{array}{lllllllll}\text { Cpd } & \mathrm{R}^{1} & \mathrm{R}^{2} & \mathrm{Cpd} & \mathrm{R}^{1} & \mathrm{R}^{2} & \mathrm{Cpd} & \mathrm{R}^{1} & \mathrm{R}^{2} \\ & & & & & & & & \\ \text { 1a } & \mathrm{H} & \mathrm{H} & \mathbf{2 a} & \mathrm{H} & \mathrm{H} & \mathbf{3 a} & \mathrm{H} & \mathrm{H} \\ \text { 1b } & \mathrm{H} & \mathrm{Me} & \mathbf{2 b} & \mathrm{H} & \mathrm{Me} & \mathbf{3 b} & \mathrm{H} & \mathrm{Me} \\ \text { 1c } & \mathrm{OMe} & \mathrm{H} & \mathbf{2 c} & \mathrm{OMe} & \mathrm{H} & \mathbf{3 c} & \mathrm{F} & \mathrm{H} \\ \text { 1d } & \mathrm{OH} & \mathrm{H} & \mathbf{2 d} & \mathrm{F} & \mathrm{H} & & & \\ \text { 1e } & \mathrm{F} & \mathrm{H} & & & & & & \end{array}$

1a-1e: para-sulfamoyl; 2a-2d: meta-sulfamoyl; 3a-3c: ortho-sulfamoyl

\begin{tabular}{|c|c|c|c|c|c|c|c|c|}
\hline \multirow[t]{2}{*}{ Compd } & \multicolumn{4}{|c|}{$K_{\mathrm{i}}(\mathrm{nM})^{*}$} & \multicolumn{4}{|c|}{ Selectivity ratios } \\
\hline & $\mathrm{hCA} \mathrm{I}^{\mathrm{a}}$ & hCA II ${ }^{\mathrm{a}}$ & hCA IX & $\overline{h C A ~ X I I ~}$ & $\mathrm{I} / \mathrm{IX}$ & $\mathrm{I} / \mathrm{XII}$ & II/IX & $\mathrm{II} / \mathrm{XII}$ \\
\hline $\mathbf{1}^{\mathrm{a}}$ & 5650 & 5200 & 69 & 9.4 & 81.9 & 601.0 & 75.4 & 553.2 \\
\hline 1b & 5590 & 5220 & 68 & 104 & 82.2 & 53.7 & 76.8 & 50.2 \\
\hline 1c & 78 & 4890 & 6.5 & 1.2 & 12.0 & 65.0 & 752.3 & 4075 \\
\hline 1d & 87 & 5290 & 1.6 & 59 & 54.4 & 1.5 & 3306 & 89.7 \\
\hline 1e & 62 & 57 & 5.8 & 76 & 10.7 & 0.8 & 9.8 & 0.75 \\
\hline $2^{\mathrm{a}}$ & 59 & 87 & 6.9 & 1.3 & 8.5 & 45.4 & 12.6 & 66.9 \\
\hline 2b & 102 & 1710 & 1.1 & 410 & 92.7 & 0.24 & 1554 & 4.2 \\
\hline 2c & 76 & 6315 & 1.7 & 9.2 & 44.7 & 8.3 & 3715 & 686 \\
\hline 2d & 78 & 2140 & 1.0 & 57 & 78.0 & 1.4 & 2140 & 37.5 \\
\hline $3 a$ & $8,06,000$ & 4950 & 6370 & 10 & 126.5 & 80,600 & 0.77 & 495 \\
\hline 3b & 674,000 & 4610 & 8600 & 86 & 78.4 & 7837 & 0.53 & 53.6 \\
\hline $3 c$ & 416,000 & 4125 & 8450 & 12 & 49.2 & 34,667 & 0.48 & 344 \\
\hline AAZ & 250 & 12 & 25 & 5.7 & 10.0 & 43.8 & 0.48 & 2.1 \\
\hline DCP & 1200 & 38 & 50 & 50 & 24.0 & 24.0 & 0.76 & 0.76 \\
\hline SA & 25,000 & 240 & 294 & 37 & 85.0 & 675 & 0.81 & 6.5 \\
\hline CLX & 50,000 & 21 & 16 & 18 & 3125 & 2778 & 1.31 & 1.16 \\
\hline VLX & 54,000 & 43 & 27 & 13 & 2000 & 4153 & 1.59 & 3.30 \\
\hline
\end{tabular}

a Full length, cytosolic isoform.

b Catalytic domain, recombinant enzyme.

* Errors in the range of $\pm 5-10 \%$ of the reported value, from three different determinations. 
Thus, very small structural changes related to the position of the sulfamoyl moiety, and the presence or absence of other substituents on the second benzene ring (moieties $R^{1}$ and $\mathrm{R}^{2}$ ) in sulfonamides $\mathbf{1 - 3}$, leads to dramatic changes of hCA I inhibition, with activity varying from the millimolar to the nanomolar. This is, as far as we know, the highest such variation ever observed for regioisomeric sulfonamides, and provides very interesting hints for the drug design of CAIs.

(ii) The ubiquitous and physiologically dominant cytosolic isoform hCA II was weakly inhibited by most of the investigated sulfonamides 1-3 (affinities in the micromolar ramge), except two derivatives, 1e and 2a, which showed inhibition constants of 57-87 $\mathrm{nM}$ (Table 1 ). Indeed, the remaining regioisomeric sulfonamides $\mathbf{1 a - 1 d}, \mathbf{2 b - 2 d}$ and $\mathbf{3 a - 3 c}$ showed $K_{\mathrm{I}} \mathrm{S}$ in the range of $1.71-5.29 \mathrm{M}$. This rather weak inhibitory activity against hCA II is a significant finding, considering that other aromatic or heterocyclic sulfonamides investigated earlier, such as the clinically used compounds AAZ, DCP, SA, CLX and VLX, show very good inhibitory action against hCA II, with $K_{\mathrm{I}} \mathrm{S}$ in the range of $12-240 \mathrm{nM}$ (Table $1) .{ }^{5}$ Since except for ophthalmologic applications, ${ }^{5}$ CA II is generally an offtarget, this feature of the alkyne sulfonamides investigated here is of considerable interest and may be an intrinsic property of this class of derivatives. It should be mentioned in fact that no X-ray crystl structures of alkyne (or alkene)-sulfonamide derivatives are reported so far, although a large number of aromatic, heterocyclic, aliphatic and sugar sulfonamides have been crystallized in complex with CA II (and several other isoforms II). ${ }^{23-25}$ It is also quite difficult to explain (without X-ray crystal structures) why the two compounds mentioned above, $\mathbf{1 e}$ and $\mathbf{2 a}$, are at least two orders of magnitude better CAIs compared to their structurally closely related congeners investigated here.

(iii) The tumor-associated hCA IX was weakly inhibited by the ortho-substituted sulfonamides 3 ( $K_{\mathrm{I}} \mathrm{S}$ in the range of 6.37$8.60 \mathrm{M}$ ) but highly inhibited by the para- and meta-substituted regioisomers $\mathbf{1}$ and $\mathbf{2}$, which showed inhibition constants in the range of $1.0-69 \mathrm{nM}$ (Table 1). For the para-substituted derivatives $\mathbf{1}$, the phenyl and $p$-tolyl derivatives 1a, 1b were the weakest inhibitors $\left(K_{\mathrm{I}} \mathrm{S}\right.$ of $\left.68-69 \mathrm{nM}\right)$, but the prsence of methoxy, hydroxy or fluorine moieties on the secoind ring led to a dramatic increase of the inhibitory power for compounds incorporating them (1c-1e), which possessed $K_{\mathrm{I}} \mathrm{S}$ in the range of 1.6-6.5 nM. For the meta series 2 , all compounds showed excellent hCA IX inhibitory activity, irrespective of the substitution pattern at the second aromatic ring (Table 1). Since hCA IX is an important drug target, ${ }^{5}$ both for diagnosis and treatment of hypoxic tumors/metastases, these data are of high interest (correlated to the fact that most of these sulfonamides did not inhibit well hCA II, the main offtarget isoform when the antitumor applications of the CAIs are considered). ${ }^{5}$

(iv) The inhibition of the second tumor-associated isoform, hCA $\mathrm{XII}$; with compounds investigated here, is also of great interest. Unexpectedly, all regioiomeric sulfonamides, including the ortho-substituted derivatives $\mathbf{3}$, showed significant inhibitory properties, with $K_{\mathrm{I}} \mathrm{S}$ in the range of $1.2-410 \mathrm{nM}$. The most effective hCA XII inhibitors were compounds 1c (para-substituted sulfonamide), 2a and 2c (meta-substituted sulfonamides) and 3c (ortho-substituted sulfonamide) which had inhibition constants in the range of 1.2-12 nM. Small structural differences at the second aromatic ring also led to important changes of activity. For example, the tolyl derivatives $\mathbf{1 b}$ and $\mathbf{2 b}$, were one order of magnitude weaker
hCA XII inhibitors compared to the corresponding phenyl ones 1a and 2a, respectively, of which they differ only by the presence of an additional methyl group.

(v) The selectivity ratios for the inhibition of hCA IX (and to a less extent, hCA XII) over hCA I and II are usually a problematic issue, since most of the classical sulfonamide CAIs (e.g., AAZ, DCP $)^{5}$ have higher affinity for hCA II than for hCA IX. As a consequence such compounds should not be used for the selective inhibition of the tumor-associated isozyme as they will preponderantly inhibit hCA II (offtarget) instead of hCA IX (target enzyme). However, for the derivatives 1-3 investigated here, this problem does not appear, due to their particular features of being highly effective hCA IX and XII inhibitors, and much less effective as inhibitors of the cytosolic isoforms hCA I and II (Table 1). Indeed, the selectivity ratios showed in Table 1 are most of the time favorable for the inhibition of the tarnsmembrane, tumor-associated isoforms hCA IX and XII, over vthe cytosolic ones, in the case of compounds 1-3. This is exactly the reverse for the clinically sued sulfonamides AAZ-VLX shown in Table 1.

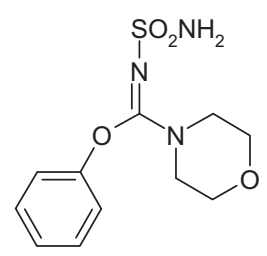

4

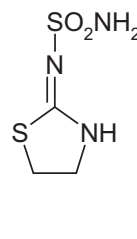

5
In order to better understand the variable inhibition pattern on the alkyne-substituted benzenesulfonamide regioisomers 1-3 investigated here, one of the reviewers of this paper suggested us to compare them with the sulfamide derivatives $\mathbf{4}$ and $\mathbf{5}$. The X-ray crystal structure of these two compounds in complex with hCA II have been recently reported ${ }^{26}$ but their inhibition pattern against various CA isozymes is not yet available. As seen from Figure 1, where the two adducts of sulfonamides $\mathbf{4}$ and $\mathbf{5}$ bound within hCA II are superposed, there are various possibilities for an inhibitor to adopt when bound within the enzyme active site. Such various orientations are possible because hCA II (and the other CA isoforms investigated here) possess rather large active sites. For all of them, half of the active site is predominantly hydrophilic (shown in red in Fig. 1) with the opposite half being hydrophobic (shown in blue in the figure). It may be observed for these two structurally related inhibitors discussed here that the organic scaffold adopts quite diverse orientations when bound within the enzyme cavity. The compact inhibitor 5 is orientated prevalently towards the hydrophobic part of it, whereas the one with a more complicated, branched scaffold (compound 4) binds with a part of the molecule lying in the hydrophobic and the other one in the hydrophilic half of the active site. We expect this type of behavior also for the regioisometric alkynylsulfonamides investigated here which due to their different positions of the sulfonamide and alkynyl fragments within the molecule may be particularly prone to this type of variable binding in different parts of the active site of this and other CA isozymes. Such a binding, which has been documented for other classes of CAIs by this and other groups, ${ }^{23-26}$ might explain the inhibition data of Table 1 .

In conclusion, we report here an investigation of compounds incorporating regioisomeric phenylethynylbenzenesulfonamide moieties as inhibitors of four physiologically relevant CA isoforms, hCA I, II, IX and XII. Inhibition between the low nanomolar to the millimolar range has been observed against them, with several low nanomolar and tumor-CA selective inhibitors detected. As this class 


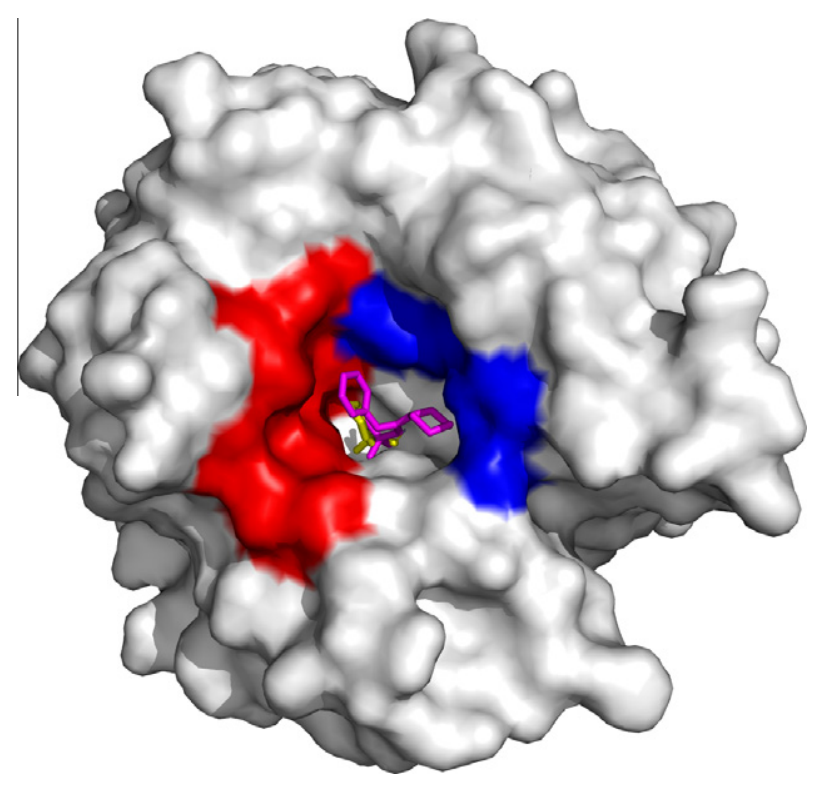

Figure 1. Superposition of the hCA II adducts with sulfamides 4 (PDB file 3M04, magenta) $)^{26}$ and 5 (PDB file $3 \mathrm{M} 14$, yellow) ${ }^{26}$ when bound within the hCA II active site. The hydrophilic half of the active site is shown in blue whereas the hydrophobic one in red. The scaffolds of the bound inhibitors may adopt highly variable orientations throughout the enzyme cavity, which may explain both the difference in inhibitory power towards hCA II as well as differential inhibition of the various CA isoforms which possess a very similar active site organization with this isoform, but around 5-10 different amino acids within their active sites compared to hCA II. $^{23,24}$

of alkyne sulfonamides is investigated for the first time here for the inhibition of CAs, our study affords interesting hints for designing isozyme-selective CAIs targeting the tumor-associated isoforms.

\section{Acknowledgments}

This research was financed in part by a grant of the 7th FP of EU (Metoxia project) and the Canadian Institutes of Health Research (MOP-14712). We are very grateful to Dr. Giuseppina De Simone (CNR Naples, Italy) for helpful discussions and for generating for us Figure 1.

\section{References and notes}

1. Anana, R.; Rao, P. N. P.; Chen, Q. H.; Knaus, E. E. Bioorg. Med. Chem. 2006, 14, 5259.

2. (a) Chowdhury, M. A.; Abdellatif, K. R.; Dong, Y.; Yu, G.; Huang, Z.; Rahman, M.; Das, D.; Velázquez, C. A.; Suresh, M. R.; Knaus, E. E. Bioorg. Med. Chem. Lett. 2010, 20, 1324; (b) Rao, P.; Knaus, E. E. J. Pharm. Pharm. Sci. 2008, 11, 81s; (c) Chen, Q. H.; Rao, P. N.; Knaus, E. E. Bioorg. Med. Chem. 2005, 13, 4694

3. (a) Supuran, C. T.; Casini, A.; Mastrolorenzo, A.; Scozzafava, A. Mini-Rev. Med. Chem. 2004, 4, 625; (b) Dogné, J. M.; Supuran, C. T.; Pratico, D. J. Med. Chem. 2005, 48, 2251.

4. (a) Di Fiore, A.; Pedone, C.; D’Ambrosio, K.; Scozzafava, A.; De Simone, G.; Supuran, C. T. Bioorg. Med. Chem. Lett. 2006, 16, 437; (b) Weber, A.; Casini, A.; Heine, A.; Kuhn, D.; Supuran, C. T.; Scozzafava, A.; Klebe, G. J. Med. Chem. 2004, $47,550$.

5. (a) Supuran, C. T. Nat. Rev. Drug Disc. 2008, 7, 168; (b) Supuran, C. T. Bioorg. Med. Chem. Lett. 2010, 20, 3467.

6. (a) Švastová, E.; Hulı́ková, A.; Rafajová, M.; Zat'ovičová, M.; Gibadulinová, A.; Casini, A.; Cecchi, A.; Scozzafava, A.; Supuran, C. T.; Pastorek, J. FEBS Lett. 2004, 577, 439; (b) Ebbesen, P.; Pettersen, E. O.; Gorr, T. A.; Jobst, G.; Williams, K. Kienninger, J.; Wenger, R. H.; Pastorekova, S.; Dubois, L.; Lambin, P.; Wouters, B. G.; Supuran, C. T.; Poellinger, L.; Ratcliffe, P.; Kanopka, A.; Görlach, A Gasmann, M.; Harris, A. L.; Maxwell, P.; Scozzafava, A. J. Enzyme Inhib. Med. Chem. 2009, 24(S1), 1; (c) Winum, J. Y.; Rami, M.; Scozzafava, A.; Montero, J. L. Supuran, C. Med. Res. Rev. 2008, 28, 445; (d) Supuran, C. T.; Scozzafava, A. Casini, A. Med. Res. Rev. 2003, 23, 146.

7. (a) Dubois, L.; Lieuwes, N. G.; Maresca, A.; Thiry, A.; Supuran, C. T.; Scozzafava, A.; Wouters, B. G.; Lambin, P. Radiother. Oncol. 2009, 92, 423; (b) Ahlskog, J. K. J.;
Dumelin, C. E.; Trüssel, S.; Marlind, J.; Neri, D. Bioorg. Med. Chem. Lett. 2009, 19, 4851; (c) Ahlskog, J. K.; Schliemann, C.; Mårlind, J.; Qureshi, U.; Ammar, A.; Pedleym, R. B.; Neri, D. Br. J. Cancer. 2009, 101, 645.

8. (a) Swietach, P.; Wigfield, S.; Cobden, P.; Supuran, C. T.; Harris, A. L.; Vaughan-Jones, R. D. J. Biol. Chem. 2008, 283, 20473; (b) Swietach, P.; Wigfield, S.; Supuran, C. T.; Harris, A. L.; Vaughan-Jones, R. D. BJU Int. 2008, 101(Suppl 4), 22.

9. (a) Alterio, V.; Hilvo, M.; Di Fiore, A.; Supuran, C. T.; Pan, P.; Parkkila, S.; Scaloni, A.; Pastorek, J.; Pastorekova, S.; Pedone, C.; Scozzafava, A.; Monti, S. M.; De Simone, G. Proc. Natl. Acad. Sci. U.S.A. 2009, 106, 16233; (b) Thiry, A.; Dogné, J. M.; Masereel, B.; Supuran, C. T. Trends Pharmacol. Sci. 2006, 27, 566.

10. (a) Pastorekova, S.; Parkkila, S.; Pastorek, J.; Supuran, C. T. J. Enzyme Inhib. Med. Chem. 2004, 19, 199; (b) Vullo, D.; Franchi, M.; Gallori, E.; Pastorek, J.; Scozzafava, A.; Pastorekova, S.; Supuran, C. T. J. Enzyme Inhib. Med. Chem. 2003, 18, 403; (c) Franchi, M.; Vullo, D.; Gallori, E.; Pastorek, J.; Russo, A.; Scozzafava, A.; Pastorekova, S.; Supuran, C. T. J. Enzyme Inhib. Med. Chem. 2003, $18,333$.

11. (a) Wykoff, C. C.; Beasley, N. J.; Watson, P. H.; Turner, K. J.; Pastorek, J.; Sibtain, A.; Wilson, G. D.; Turley, H.; Talks, K. L.; Maxwell, P. H.; Pugh, C. W.; Ratcliffe, P. J.; Harris, A. L. Cancer Res. 2000, 60, 7075; (b) Bartosova, M.; Parkkila, S.; Pohlodek, K.; Karttunen, T. J.; Galbavy, S.; Mucha, V.; Harris, A. L.; Pastorek, J.; Pastorekova, S. J. Pathol. 2002, 197, 1; Pastoreková, S.; Pastorek, J. Cancerrelated carbonic anhydrase isozymes and their inhibition. In Carbonic Anhydrase: Its Inhibitors and Activators; Supuran, C. T., Scozzafava, A., Conway, J., Eds.; CRC Press: Boca Raton, FL, 2004; p 255.

12. (a) Said, H. M.; Supuran, C. T.; Hageman, C.; Staab, A.; Polat, B.; Katzer, A.; Scozzafava, A.; Anacker, J.; Flentje, M.; Vordermark, D. Curr. Pharm. Des. 2010, 16, 3288; (b) Zatovicova, M.; Jelenska, L.; Hulikova, A.; Csaderova, L.; Ditte, Z.; Ditte, P.; Goliasova, T.; Pastorek, J. M.; Pastorekova, S. Curr. Pharm. Des. 2010, $16,3255$.

13. (a) Vullo, D.; Innocenti, A.; Nishimori, I.; Pastorek, J.; Scozzafava, A.; Pastorekova, S.; Supuran, C. T. Bioorg. Med. Chem. Lett. 2005, 15, 963; (b) Battke, C.; Kremmer, E.; Mysliwietz, J.; Gondi, G.; Dumitru, C.; Brandau, S.; Lang, S.; Vullo, D.; Supuran, C.; Zeidler, R. Cancer Immunol. Immunother. 2011, 60, 649; (c) Pacchiano, F.; Carta, F.; McDonald, P. C.; Lou, Y.; Vullo, D.; Scozzafava, A.; Dedhar, S.; Supuran, C. T. J. Med. Chem. 2011, 54, 1896.

14. Lou, Y.; McDonald, P. C.; Oloumi, A.; Chia, S. K.; Ostlund, C.; Ahmadi, A.; Kyle, A.; Auf dem Keller, U.; Leung, S.; Huntsman, D. G.; Clarke, B.; Sutherland, B. W.; Waterhouse, D.; Bally, M. B.; Roskelley, C. D.; Overall, C. M.; Minchinton, A.; Pacchiano, F.; Carta, F.; Scozzafava, A.; Touisni, N.; Winum, J. Y.; Supuran, C. T.; Dedhar, S. Cancer Res. 2011, 71, 3364

15. (a) Supuran, C. T. Curr. Pharm. Des. 2008, 14, 641; (b) Supuran, C. T.; Scozzafava, A. Bioorg. Med. Chem. 2007, 15, 4336; (c) Temperini, C.; Cecchi, A.; Scozzafava, A.: Supuran, C. T. Bioorg. Med. Chem. Lett. 2008, 18, 2567; (d) Supuran, C. T. Curr. Pharm. Des. 2008, 14, 603; (e) Temperini, C.; Cecchi, A.; Scozzafava, A.; Supuran, C. T. Org. Biomol. Chem. 2008, 6, 2499; (f) Temperini, C.; Cecchi, A.; Scozzafava, A.; Supuran, C. T. J. Med. Chem. 2009, 52, 322; (g) Winum, J. Y.; Temperini, C.; El Cheikh, K.; Innocenti, A.; Vullo, D.; Ciattini, S.; Montero, J. L.; Scozzafava, A.; Supuran, C. T. J. Med. Chem. 2006, 49, 7024.

16. Supuran, C. T.; Scozzafava, A.; Casini, A. Development of sulfonamide carbonic anhydrase inhibitors (CAIs). In Carbonic anhydrase-Its Inhibitors and Activators; Supuran, C. T., Scozzafava, A., Conway, J., Eds.; CRC Press: Boca Raton (FL), 2004; p 67.

17. Khalifah, R. G. J. Biol. Chem. 1971, 246, 2561. An Applied Photophysics stopped-flow instrument has been used for assaying the CA catalysed $\mathrm{CO}_{2}$ hydration activity. Phenol red (at a concentration of $0.2 \mathrm{mM}$ ) has been used as indicator, working at the absorbance maximum of $557 \mathrm{~nm}$, with $20 \mathrm{mM}$ Hepes ( $\mathrm{pH} 7.5$ ) as buffer, and $20 \mathrm{mM} \mathrm{Na}_{2} \mathrm{SO}_{4}$ (for maintaining constant the ionic strength), following the initial rates of the CA-catalyzed $\mathrm{CO}_{2}$ hydration reaction for a period of $10-100 \mathrm{~s}$. The $\mathrm{CO}_{2}$ concentrations ranged from 1.7 to $17 \mathrm{mM}$ for the determination of the kinetic parameters and inhibition constants. For each inhibitor at least six traces of the initial $5-10 \%$ of the reaction have been used for determining the initial velocity. The uncatalyzed rates were determined in the same manner and subtracted from the total observed rates. Stock solutions of inhibitor $(0.1 \mathrm{mM})$ were prepared in distilled-deionized water and dilutions up to $0.01 \mathrm{nM}$ were done thereafter with distilled-deionized water. Inhibitor and enzyme solutions were preincubated together for $15 \mathrm{~min}$ at room temperature (prior to assay, in order to allow for the formation of the E-I complex. The inhibition constants were obtained by non-linear least-squares methods using PRISM 3 and the Cheng-Prusoff equation, ${ }^{18}$ and represent the mean from at least three different determinations. CA isofoms were recombinant ones obtained in house as reported earlier. ${ }^{19-21}$.

18. Cheng, Y.; Prusoff, W. H. Biochem. Pharmacol. 1973, 22, 3099.

19. Casey, J. R.; Morgan, P. E.; Vullo, D.; Scozzafava, A.; Mastrolorenzo, A.; Supuran, C. T. J. Med. Chem. 2004, 47, 2337.

20. Carta, F.; Temperini, C.; Innocenti, A.; Scozzafava, A.; Kaila, K.; Supuran, C. T. J. Med.Chem. 2010, 53, 5511.

21. (a) Özensoy, O.; De Simone, G.; Supuran, C. T. Curr. Med. Chem. 2010, 17, 1516; (b) De Simone, G.; Supuran, C. T. Biochim. Biophys. Acta 2010, 1804, 404.

22. Supuran, C. T. Future Med. Chem. 2011, 3, 1165.

23. Alterio, V.; DiFiore, A.; D’Ambrosio, K.; Supuran, C. T.; De Simone, G. X-Ray crystallography of CA inhibitors and its importance in drug design. In Drug Design of Zinc-Enzyme Inhibitors: Functional, Structural, and Disease Applications; Supuran, C. T., Winum, J. Y., Eds.; Wiley: Hoboken, 2009; p 73. 
24. (a) Wagner, J. M.; Avvaru, B. S.; Robbins, A. H.; Scozzafava, A.; Supuran, C. T.; McKenna, R. Bioorg. Med. Chem. 2010, 18, 4873; (b) Pacchiano, F.; Aggarwal, M.; Avvaru, B. S.; Robbins, A. H.; Scozzafava, A.; McKenna, R.; Supuran, C. T. Chem. Commun. (Camb) 2010, 46, 8371.

25. (a) De Simone, G.; Di Fiore, A.; Menchise, V.; Pedone, C.; Antel, J: Casini, A. Scozzafava, A.; Wurl, M.; Supuran, C. T. Bioorg. Med. Chem. Lett. 2005, 15, 2315; (b) Casini, A.; Antel, J.; Abbate, F.; Scozzafava, A.; David, S.; Waldeck, H.; Schafer, S.; Supuran, C. T. Bioorg. Med. Chem. Lett. 2003, 13, 841; (c) Abbate, F.;
Casini, A.; Owa, T.; Scozzafava, A.; Supuran, C. T. Bioorg. Med. Chem. Lett. 2004 14, 217; (d) Abbate, F.; Casini, A.; Scozzafava, A.; Supuran, C. T. Bioorg. Med. Chem. Lett. 2004, 14, 2357.

26. The X-ray crystal structures of compounds $\mathbf{4}$ and $\mathbf{5}$ in adduct with hCA Il are deposited in PDB as files 3M04 and 3M14 by Schulze Wischeler, J.; Sandner, N.U.; Haake, M.; Supuran, C.T.; Heine, A.; Klebe, G. and available free at: http://www.rcsb.org/pdb/explore/explore.do?structureId=3M04/ 3M14. 